\title{
Drafting a Surgical Procedure Using a Computational Anatomy Driven Approach for Precise, Robust, and Safe Vestibular Neuroprosthesis Placement-When One Size Does Not Fit All
}

Citation for published version (APA):

Seppen, B. F., van Hoof, M., Stultiens, J. J. A., van den Boogert, T., Guinand, N., Guyot, J-P., Kingma, H., Fornos, A. P., Handschuh, S., Glueckert, R., Jacobi, L., Schrott-Fischer, A., Johnson Chacko, L., \& van de Berg, R. (2019). Drafting a Surgical Procedure Using a Computational Anatomy Driven Approach for Precise, Robust, and Safe Vestibular Neuroprosthesis Placement-When One Size Does Not Fit All. Otology \& Neurotology, 40(5S Suppl 1), S51-S58. https://doi.org/10.1097/MAO.0000000000002211

Document status and date:

Published: 01/06/2019

DOl:

10.1097/MAO.0000000000002211

Document Version:

Publisher's PDF, also known as Version of record

\section{Document license:}

Taverne

\section{Please check the document version of this publication:}

- A submitted manuscript is the version of the article upon submission and before peer-review. There can be important differences between the submitted version and the official published version of record. People interested in the research are advised to contact the author for the final version of the publication, or visit the DOI to the publisher's website.

- The final author version and the galley proof are versions of the publication after peer review.

- The final published version features the final layout of the paper including the volume, issue and page numbers.

Link to publication

\footnotetext{
General rights rights.

- You may freely distribute the URL identifying the publication in the public portal. please follow below link for the End User Agreement:

www.umlib.nl/taverne-license

Take down policy

If you believe that this document breaches copyright please contact us at:

repository@maastrichtuniversity.nl

providing details and we will investigate your claim.
}

Copyright and moral rights for the publications made accessible in the public portal are retained by the authors and/or other copyright owners and it is a condition of accessing publications that users recognise and abide by the legal requirements associated with these

- Users may download and print one copy of any publication from the public portal for the purpose of private study or research.

- You may not further distribute the material or use it for any profit-making activity or commercial gain

If the publication is distributed under the terms of Article $25 \mathrm{fa}$ of the Dutch Copyright Act, indicated by the "Taverne" license above,

Download date: 26 Apr. 2023 


\title{
Drafting a Surgical Procedure Using a Computational Anatomy Driven Approach for Precise, Robust, and Safe Vestibular Neuroprosthesis Placement-When One Size Does Not Fit All
}

\author{
$*$ Bart F. Seppen, *Marc van Hoof, *Joost J. A. Stultiens, *Thomas van den Boogert, $\nmid$ Nils Guinand, \\ $\dagger$ Jean-Philippe Guyot, *†Herman Kingma, †Angelica Pérez Fornos, §Stephan Handschuh, \\ đRudolf Glueckert, ||Linda Jacobi, \Annelies Schrott-Fischer, \\ ФLejo Johnson Chacko, and $* \ddagger$ Raymond van de Berg \\ * Department of Otorhinolaryngology and Head and Neck Surgery, Maastricht University Medical Centre, Maastricht, Netherlands, \\ tDivision of Otorhinolaryngology and Head-and-Neck Surgery, Department of Clinical Neurosciences, Geneva University Hospitals, \\ Geneva, Switzerland; $\ddagger$ Faculty of Physics, Tomsk State University, Tomsk, Russia; §VetCore Facility for Research, Veterinary \\ University Vienna, Vienna; $\Phi$ Department of Otorhinolaryngology, Medical University Innsbruck, Innsbruck, Austria; and \\ ||Department of Radiology and Nuclear Medicine, Maastricht University Medical Center, Maastricht, The Netherlands
}

Objective: To design and evaluate a new vestibular implant and surgical procedure that should reach correct electrode placement in $95 \%$ of patients in silico.

Design: Computational anatomy driven implant and surgery design study.

Setting: Tertiary referral center.

Participants: The population comprised 81 patients that had undergone a CT scan of the Mastoid region in the Maastricht University Medical Center. The population was subdivided in a vestibular implant eligible group (28) and a control group (53) without known vestibular loss.

Interventions: Canal lengths and relationships between landmarks were calculated for every patient. The relationships in group-anatomy were used to model a fenestration site on all three semicircular canals. Each patient's simulated individual distance from the fenestration site to the ampulla was calculated and compared with the populations average to determine if placement would be successful.

Main Outcome Measures: Lengths of the semicircular canals, distances from fenestration site to ampulla (intrala- byrinthine electrode length), and rate of successful electrode placement (robustness).

Results: The canal lengths for the lateral, posterior, and superior canal were respectively $12.1 \mathrm{~mm} \pm 1.07,18.8 \mathrm{~mm} \pm 1.62$, and $17.5 \mathrm{~mm} \pm 1.23$, the distances from electrode fenestration site to the ampulla were respectively $3.73 \mathrm{~mm} \pm 0.53$, $9.02 \mathrm{~mm} \pm 0.90$, and $5.31 \mathrm{~mm} \pm 0.73$ and electrode insertions were successful for each respective semicircular canal in $92.6 \%$, $66.7 \%$, and $86.4 \%$ of insertions in silico. The implant electrode was subsequently revised to include two more electrodes per lead, resulting in a robustness of $100 \%$.

Conclusions: The computational anatomy approach can be used to design and test surgical procedures. With small changes in electrode design, the proposed surgical procedure's target robustness was reached. Key Words: Computational anatomy-Electrode lead-Semicircular canal-Vestibular implant-Vestibular loss-Vestibular prothesis-Vestibular surgery.

Otol Neurotol 40:S51-S58, 2019.
Principles and Strategies in Designing Surgical Interventions

Surgical procedures are conventionally designed based on expert insights, professional preferences and personal

Address correspondence and reprint requests to Raymond van de Berg, Department of Otorhinolaryngology and Head \& Neck Surgery, Maastricht University Medical Centre, School for Mental Health and Neuroscience, Maastricht, The Netherlands; E-mail: Raymond.vande. berg@mumc.nl

B.S. and M.v.H. have contributed equally.

The authors disclose no conflicts of interest.

DOI: $10.1097 / M A O .0000000000002211$ experience, resembling traditional craftsmanship. Currently, only a selection of potentially innovative procedures can be thoroughly evaluated in clinical practice. Therefore, the development of new surgical procedures is limited and complex. Over time, the burden of complications in case of possible harms or the incidence of suboptimal clinical results accumulates before its abandonment or succession. Moreover, the time spent using a suboptimal intervention contrasts with the total harms done and benefits received implementing better interventions. In consequence, time taken to reduce the amount of resources and time required for surgical 
innovation should be reduced. Indeed, it has been widely recognized that methods for surgical innovation should be restructured, which led to the development of the IDEAL framework $(1,2)$. This framework describes the stages of innovation in surgery and makes a set of recommendations for each stage. It was set to reduce the amount of resources and time required for surgical innovation. The process of implementing new surgical procedures has been started but should be further studied to make quicker advancements in the strategy for improvement and innovation in clinical care.

\section{Incentive and Challenge Identification for Apprehending Vestibular Deficiency}

Here, the strategy and further development of a novel type of neuroprosthesis, a vestibular implant is considered (3-6). The vestibular implant aims to address peripheral vestibular function loss, which hitherto has remained clinically unattended to (7). Bilateral vestibular deficiency affects approximately 28 out of 100,000 adults $(64,046$ in total) in the United States of America (8). Every year, between 6405 and 25,618 quality-adjusted life years (QALYs), based on a healthy utility gain of 0.1 to 0.4 for 50 to $100 \%$ restoration (7), are thus approximately collectively lost in the United States of America alone until a treatment is available. With a cost-effective threshold of $\$ 50,000$ per QALY, this results in $\$ 320$ million to $\$ 1.3$ billion per year that can be commercially exploited.

The current prototype vestibular implant operates with up to three electrode leads in the semicircular canals of the inner ear. Each lead contains a single electrode on the distal tip, intended for surgical placement in the ampulla of the lateral, posterior and superior semicircular canal. In this way, the electrodes are presumably close to the innervating vestibular nerve fibers $(9,10)$. This device aims to replace the missing information from impaired vestibular organs by stimulating these nerve fibers, to restore the subject's abilities such as gaze stabilization (oscillopsia, impaired vestibulo-ocular reflex), spatial orientation, and body posture control.

The surgical procedure faces several challenges, particularly that of hearing preservation. Minimal invasiveness is thought to be essential when handling the (membranous) labyrinth, incorporated in the vestibule, semicircular canals, and cochlea. The correct placement of the intralabyrinthine electrodes requires entering the labyrinth for optimal vestibular excitation (11-13). In stark contrast with cochlear implant surgery, the electrode placement of the individual vestibular implant leads can fail not just once, but in all three cupulas of the semicircular canals. The procedure is further complicated by the inter-individual variation in morphology of the labyrinth and lack of visibility $(14,15)$. During surgery the target structure and electrode cannot be directly inspected or visualized. The distance from the point of introduction of the electrode lead, through the semicircular canal to the ampulla is unknown for each individual subject. Electrodes could be placed not far enough, failing to adequately stimulate the nerve endings, or too far, increasing the chance of cross-excitation, damage to the membranous labyrinth and/or possibly hearing loss. The surgeon can possibly feel the resistance during lead insertion by means of tactile feedback. However, this is subjective and the relationship to trauma induction or the rate of success is unknown. Alternatives such as neuronavigation are currently unlikely to reach the required accuracy and robustness to achieve this goal directly (16). Furthermore, the surgical approach employed in reaching the surgical plane for the semicircular canals fenestration, also influences the distance from the entrance of the semicircular canal to the ampulla. So, variability in the surgical procedure, in combination with inter-individual anatomical diversity, and obscured positioning in relation to the targets (semicircular canal ampullae) in absence of objective feedback, all influence correct electrode placement and the presence of harms. This complexity and interplay, challenges the ability to have just one surgical procedure and one vestibular implant electrode design with a high overall success rate.

\section{Drafting a Procedure for a Vestibular Implant Using Computational Anatomy}

Surgical procedure and implant design (i.e., electrode length) can be studied simultaneously to evaluate its paired success in terms of performance metrics. This would reduce the complexity that exists when considering every individual factor alone. For that purpose and to prevent many trial-and-error attempts in vivo, the surgical procedure in this investigation is performed in silico. Open source imaging software is used to simulate the surgical steps on the target population of interest, by using computed tomography (CT) scans of vestibular implant eligible patients (17). Using a computational anatomy approach $(18,19)$, the length of the three electrodes can be calculated together with the accuracy and robustness of the surgical procedure in the target population.

Specifically, the objective of the procedure presented here was to design and evaluate the surgical procedure and vestibular implant individual electrode lengths to attain a position within $1.0 \mathrm{~mm}$ from the center of the ampulla and a success rate of $95 \%$ of correctly placed electrodes in the target population.

\section{MATERIALS AND METHODS}

\section{Ethics}

This study was performed using readily available patient records and CT-scans of Maastricht University Medical Centre $(\mathrm{MUMC}+)$. All collected data were anonymized. The procedures in this investigation were in accordance with legislation (the Medical Research Involving Human Subjects Act) and ethical standards on human experimentation in the Netherlands. No approval was sought from an ethics committee, as this is not required for retrospective studies. All patients of MUMC+ consent for retrospective studies upon treatment unless they have previously explicitly opted-out. 


\section{Patient Inclusion, Imaging, and Screening}

Two groups of adult patients were considered for participation. The first group consisted of patients, eligible for future vestibular implantation (vestibular implant eligible group). Inclusion criteria consisted of a significant decline in peripheral vestibular function and depleted rehabilitation options. The former was defined as having a summed maximum slow phase velocity below 20 degrees/s, measured with electronystagmography during bithermal caloric testing, and/or low or no gain at rotatory chair tests. The second group (control group) consisted of patients without known vestibular function loss with an available high quality CT-scans of the mastoid region in the radiology database.

Eligibility screening was performed by one author (B.S.), where after the CT-scans were judged on quality criteria. For scans to be included, the imaging needed to visualize the inner and middle ear, and have a maximal slice thickness of $0.6 \mathrm{~mm}$. Exclusion criteria consisted of CT-scan artefacts, obscuring the region of interest, insufficient quality as assessed by the first author (B.S.), significant pathology of the middle ear (e.g., cholesteatoma, chronic otitis media) and previous surgery of the middle ear. In patients with two eligible sides (left and right ear), one side was randomly selected.

\section{Imaging Analysis}

Image analysis and visualization were performed using the open source 3D Slicer 4.3 software (The Brigham and Women's Hospital, Inc., Boston, MA) package (17). The ossicular chain, the facial nerve, the tegmen tympani, and the semicircular canals were manually segmented to reflect the most critical components in otologic surgery. Fiducials were manually applied (by B.S.) to the approximate center of the semicircular canals and the three ampullae (Fig. 1).
Appurtenant 3D-coordinates were extrapolated to datapoints, using Mathematica 10.4 (Wolfram research, IL). The data-points on the semicircular canals were interpolated to 100 evenly distributed data-points. All distances were calculated in Euclidean 3-dimensional space.

\section{Surgical Planning and Evaluation}

The distance from the fenestration site, i.e., where electrode lead insertion takes place, to the center of the ampulla (ampullar distance) was calculated for each semicircular canal for all patients. The aim was to rely on preexisting surgical landmarks for the identification of the fenestration site. The fenestration site for the lateral semicircular canal (LSCC) and posterior semicircular canal (PSCC) could accordingly be selected. However, no surgical landmarks were readily available for identifying the optimal fenestration site of the superior semicircular canal (SSCC). Therefore, in a simulation, 100 evenly distributed candidate fenestration sites over the course of the SSCC were selected per patient. For each candidate fenestration site the corresponding ampullar distance was calculated. Consequently, the ratios of the distances between the already chosen fenestration sites of the LSCC, PSCC, and all candidate-SSCCfenestration-sites (inter-fenestration distance, IFD) were calculated. Ultimately, the ratio between the IFDs that corresponded with the lowest average deviation in the SSCC ampullar distance for all patients was selected. In other words, one optimal ratio that corresponded to the SSCC fenestration site that would statistically achieve the most precise electrode placement, on average, for all patients was selected (Fig. 2).

In the simulation the patients' individual IFD of the LSCC fenestration site to the PSCC fenestration site was utilized by multiplying this distance with the calculated optimal ratios for the IFD's PSCC-SSCC and LSCC-SSCC. The two resulting
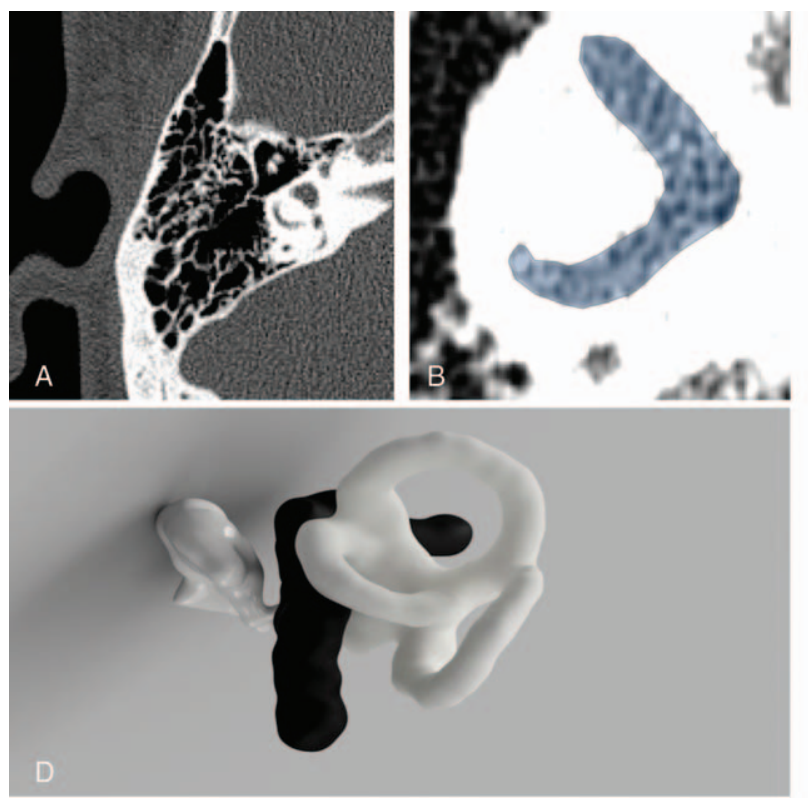

FIG. 1. Illustration of the computational anatomy approach. $A, \mathrm{CT}$ of the head with a close up of the lateral semicircular canal. After individual segmentation (as displayed in $B$ ) the facial nerve, incus, partial malleus, and the semicircular canals are separately segmented and displayed in $C$ (not represented to scale). $D$, The resulting composition of $(C)$. $E$, Measurements are taken of the center line of the semicircular canals and specific points are annotated in 3D $(X, Y, Z)$ for further calculations on models such as displayed in $D$. The black dot represents the tip of the incus and the lines of dark grey, grey, and transparant dots respectively represent the LSCC, PSCC, and SSCC (not to scale). 


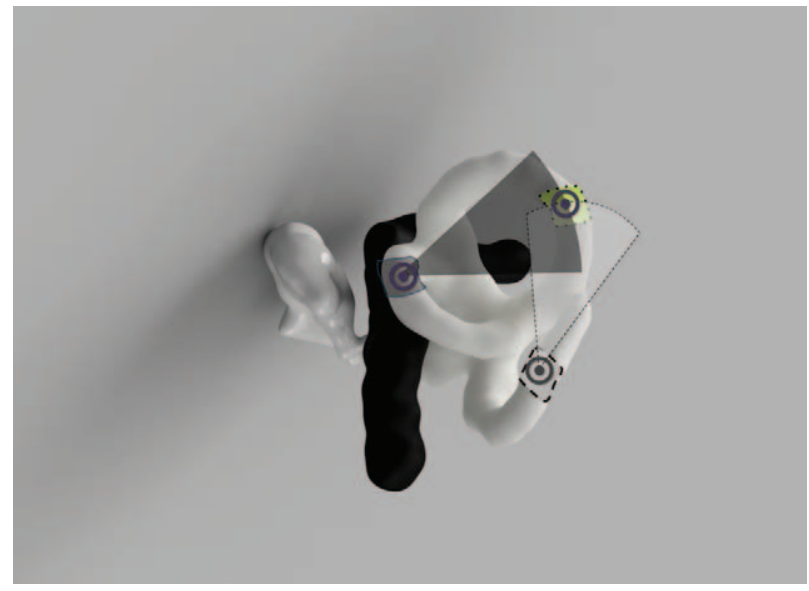

FIG. 2. Surgical guide for targeted superior canal fenestration using triangulation. In the dark grey, transparant (dashed line), and light grey (dotted line) fields, the fenestration site of the lateral, posterior, and superior semicircular canal (LSCC, PSCC, SSCC) is illustrated with a target vector. The shortest distance between two fenestration sites on different canals is referred to as an interfenestration distance (IFD). The light and dark "triangles" schematically (2D representation) represent a part of the range of possibilities, using the ratios amongst the IFDs, to encounter the SSCC fenestration site.

distances are the IFD's LSCC-SSCC and PSCC-SSCC. On a two dimensional plane these two distances, originating at their own separate fenestration sites, would give a circle of opportunities, in which the calculated distances equal the radii (Fig. 2). The two circles intersect at two points, which, in three dimensional space, would form a circle in which the two globes intersect. In the end, the individuals' closest candidate SSCC fenestration site to the "intersection circle" was selected as fenestration site for the SSCC, for each patient. So ultimately, ratios amongst IFD's were the surgical guide to the SSCC.

The main outcome of the simulation in silico was the rate of successful electrode placement. The proposed electrode lead length, a secondary outcome, was calculated by using the average of the ampullar distance per SCC (representing the model for the electrode). This distance was then compared with individual ampullar distances, for every patient's SCC. Electrode implantation was considered successful if there was a difference of less than $1.0 \mathrm{~mm}$ between the length of the individual ampullar distance and the length of the average ampullar distance. To evaluate potential surgical difficulties, structures vulnerable to adverse events such as the tegmen tympani and facial nerve were marked and the distance to the surgical landmarks was calculated.

\section{Statistical Analysis}

Statistical analysis was performed using Wolfram Mathematica 10.4 (Wolfram research, IL) and SPSS 24.0 (IBM Corp, Armonk, NY). Descriptive statistics were used for the evaluation of the surgical simulation. The outcomes of the two different groups were compared, to evaluate whether possible anatomical differences between the two patient groups would influence the result. Main outcome measures (e.g., ampullar distance and IFD) were compared using a Student's $t$ test for unpaired comparison of two groups in normally distributed data. The side of analysis (Table 1) and the proximity of the surgical guide to the superior canal were compared using the $\chi^{2}$ test. A $p$-value of $<0.05$ was considered statistically significant.
TABLE 1. Patient demographics

\begin{tabular}{lccr}
\hline & $\begin{array}{c}\text { VI Eligible } \\
\text { Group n=28 }\end{array}$ & $\begin{array}{c}\text { Control Group } \\
\mathrm{n}=53\end{array}$ & $p$-Value \\
\hline Patient demographics & & & \\
$\quad$ Mean age (SD) & $62(12)$ & $56.5(19)$ & 0.168 \\
Female gender & $36 \%$ & $51 \%$ & \\
Diagnosis & & & 0.232 \\
$\quad$ No pathology & $89 \%$ & $66 \%$ & \\
Middle ear pathology & $7 \%$ & $23 \%$ & \\
SSC dehiscence & $4 \%$ & $8 \%$ & \\
Other & $0 \%$ & $4 \%$ & \\
Median year of scan & 2013 & 2016 & $<0.01 *$ \\
$\quad$ (min-max) & $(2006-2016)$ & $(2016-2016)$ & \\
Side of analysis (right) & $50 \%$ & $47 \%$ & 0.308 \\
\hline
\end{tabular}

Baseline characteristics are displayed. Statistical significant differences are observed $\left(^{*}\right)$. Min indicates minimum; Max, maximum; SD, standard deviation.

\section{RESULTS}

\section{Patients}

A total of 81 patients were included, 28 patients in the vestibular implant eligible group and 53 patients in the Control group (Table 1). The Control group consisted of patients who underwent a CT scan with a slice thickness of $0.4 \mathrm{~mm}(\mathrm{n}=53$, Somatom Flash and Force CT, Siemens, Germany). The Vestibular implant eligible group was imaged with a slice thickness of $0.4 \mathrm{~mm}$ (Flash), $0.4 \mathrm{~mm}$ (Force), $0.6 \mathrm{~mm}$ (Sensation 16, Siemens, Germany) or $0.6 \mathrm{~mm}$ (Brilliance 64, Philips, The Netherlands). The cause of vestibular loss varied in the vestibular implant eligible group, frequent diagnosis included autosomal dominant nonsyndromic deafness 9 and Menière's disease.

\section{Surgical Procedure}

It was assumed that a flawless canal wall up mastoidectomy was performed before simulation. The algorithm simulated a surgical procedure, following the sequence outlined in Figure 3. The procedure started at the tip of the incus. The closest point on the LSCC was identified and selected as fenestration site. Hereafter, Donaldson's Line, an imaginary line drawn posteriorly from the course of the LSCC, was identified (15). The intersection of Donaldson's line and the PSCC was considered as the second site for electrode fenestration site. Lastly, the algorithm that has previously been described under the heading "surgical planning and evaluation" encountered the SSCC fenestration site. Note that specific surgical tools should be developed to be able to use this method in vivo.

\section{Primary Outcome Measures}

The placement of the electrodes within $1.0 \mathrm{~mm}$ of the center of the ampulla for the LSCC, PSCC, and SSCC was successful in respectively $92.6 \%, 66.7 \%$, and $86.4 \%$ of simulations. Notably, at least one electrode was placed successfully in every patient (Fig. 4). The mean distance and SD from the fenestration site to the ampulla, and thus 
TABLE 2. Anatomic measurements and comparison between groups

\begin{tabular}{lcccccccc}
\hline & \multicolumn{3}{c}{ VI Eligible Group $\mathrm{n}=28$} & & \multicolumn{3}{c}{ Control Group $\mathrm{n}=53$} \\
\cline { 2 - 3 } & Mean (SD) & Median & IQR (Q1-Q3) & & Mean (SD) & Median & IQR (Q1-Q3) & $p$-Value \\
\hline Lateral SSC (mm) & $11.88(1.21)$ & 11.95 & $1.66(11.0-12.7)$ & & $12.22(0.97)$ & 12.14 & $1.40(11.4-12.8)$ & 0.182 \\
Posterior SSC (mm) & $18.64(1.56)$ & 18.67 & $2.45(17.5-19.9)$ & & $18.93(1.65)$ & 19.03 & $2.68(17.7-20.3)$ & 0.438 \\
Superior SSC (mm) & $17.63(1.44)$ & 17.53 & $1.87(16.7-18.6)$ & & $17.44(1.18)$ & 17.49 & $1.63(16.7-18.3)$ & 0.524 \\
\hline
\end{tabular}

Baseline semicircular canal (SSC) lengths. No statistical differences (in means) were observed. IQR indicates interquartile range; Q1 and Q3, first and third quartile respectively.

the proposed electrode lead length for the LSCC, PSCC, and SSCC were $3.73 \pm 0.53 \mathrm{~mm}, 9.02 \pm 0.90 \mathrm{~mm}$ and $5.13 \pm 0.73 \mathrm{~mm}$ respectively. Differences between maximal ampullar distances and minimal ampullar distances were $2.8 \mathrm{~mm}(4.7,7.5 \mathrm{~mm}), 4.0 \mathrm{~mm}(6.9,10.9 \mathrm{~mm})$, $8.5 \mathrm{~mm}(4.1,12.6 \mathrm{~mm})$, respectively. No significant differences between the two groups were encountered in anatomy of the investigated patients (Table 2). The closest proximity in the operational field to adverse event prone structures was $0.1 \mathrm{~mm}$ and $0.6 \mathrm{~mm}$ for the tegmen and facial nerve's (Table 3).

The minimum variation in ampullar distance deviation in the SSCC was found with a ratio of 0.59 between the IFD LSCC-SSCC and IFD PSCC-SSCC. The consequent average ratios for the IFDs LSCC-SSCC/LSCC-PSCC and PSCC-SSCC/LSCC-PSCC were 1.49 and 0.87. Utilizing these ratios, the distance of the simulation to the center of the SSCC was on average $0.42 \mathrm{~mm}$ (SD $0.30 \mathrm{~mm}$ ), with a maximum of $1.33 \mathrm{~mm}$ and minimum of $0.02 \mathrm{~mm}$. Assuming an average semicircular canal inner diameter of $0.9 \mathrm{~mm}$ for the SSCC and a perfectly round canal, in 46 cases the ratio would have led us directly to the SSCC, in 76 to within $0.5 \mathrm{~mm}$ of the SSCC and in all cases within $1 \mathrm{~mm}$ of the SSCC (Table 4) (11).

To reach the initial goal of the study an extra simulation with an altered electrode design was performed. By adding two extra electrode contacts per lead at a distance of -1.0 and $1.0 \mathrm{~mm}$ from the current electrode contact, the success rate per canal was elevated to respectively $100,98.8$, and $100 \%$ for the LSCC, PSCC, and the SSCC.
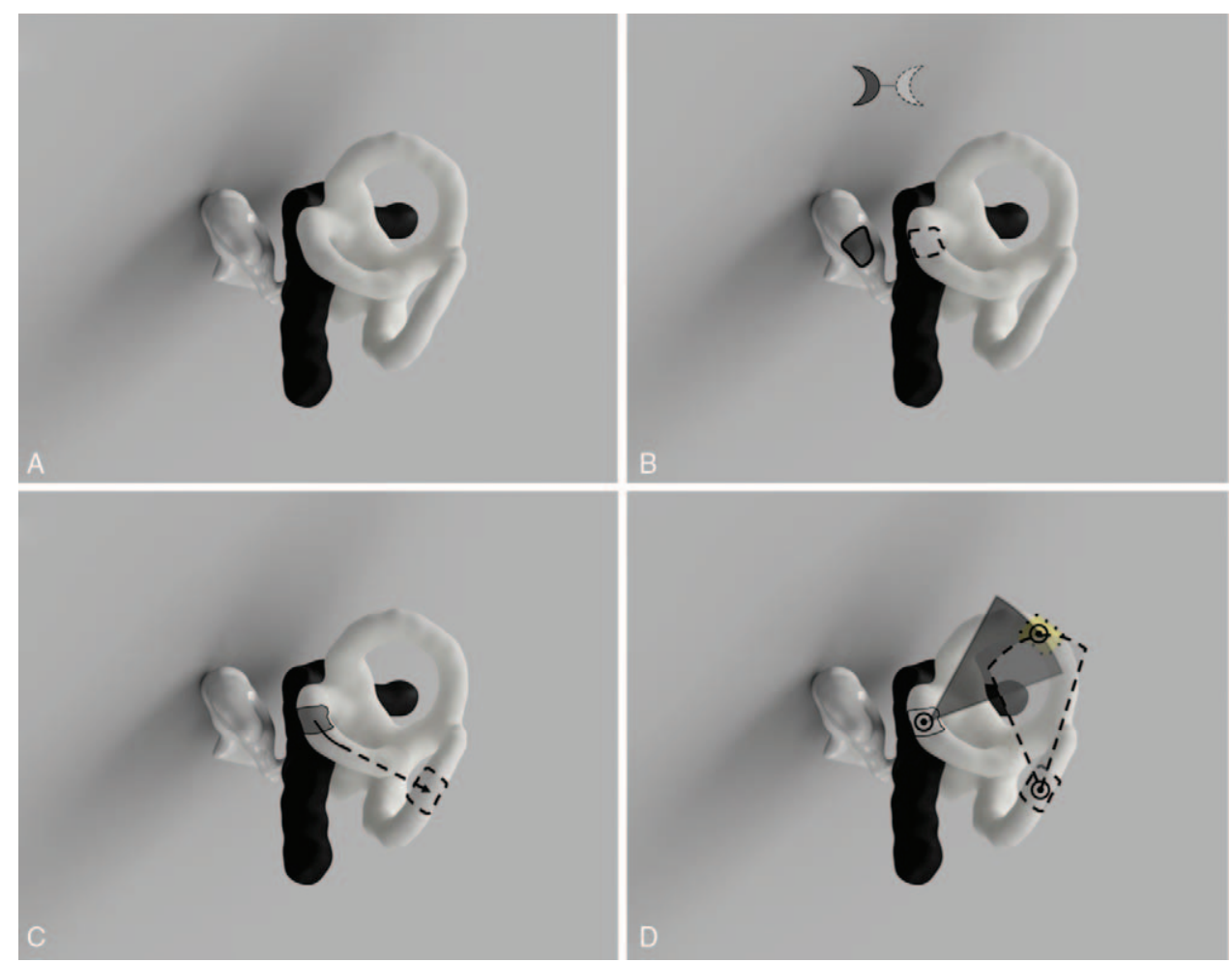

FIG. 3. Landmarks and steps in the surgical procedure. $A$, Initially the surgeon acquires the correct surgical plane. $B$, The tip of the Incus is identified (emphasized in dark grey (black line)) and the closest point of the lateral semicircular canal (illustrated in region circled by dashed line) is selected as the fenestration site for lead insertion. $C$, Donaldson's line, represented by the black dashed line, is followed over the lateral semicircular canal to the point where it intersects the posterior semicircular canal, illustrated by the box with the dashed line. This box illustrates the fenestration site of the posterior semicircular canal. $D$, As illustrated in Figure 2, ratios are used to localize the optimal superior semicircular canal fenestration site. 

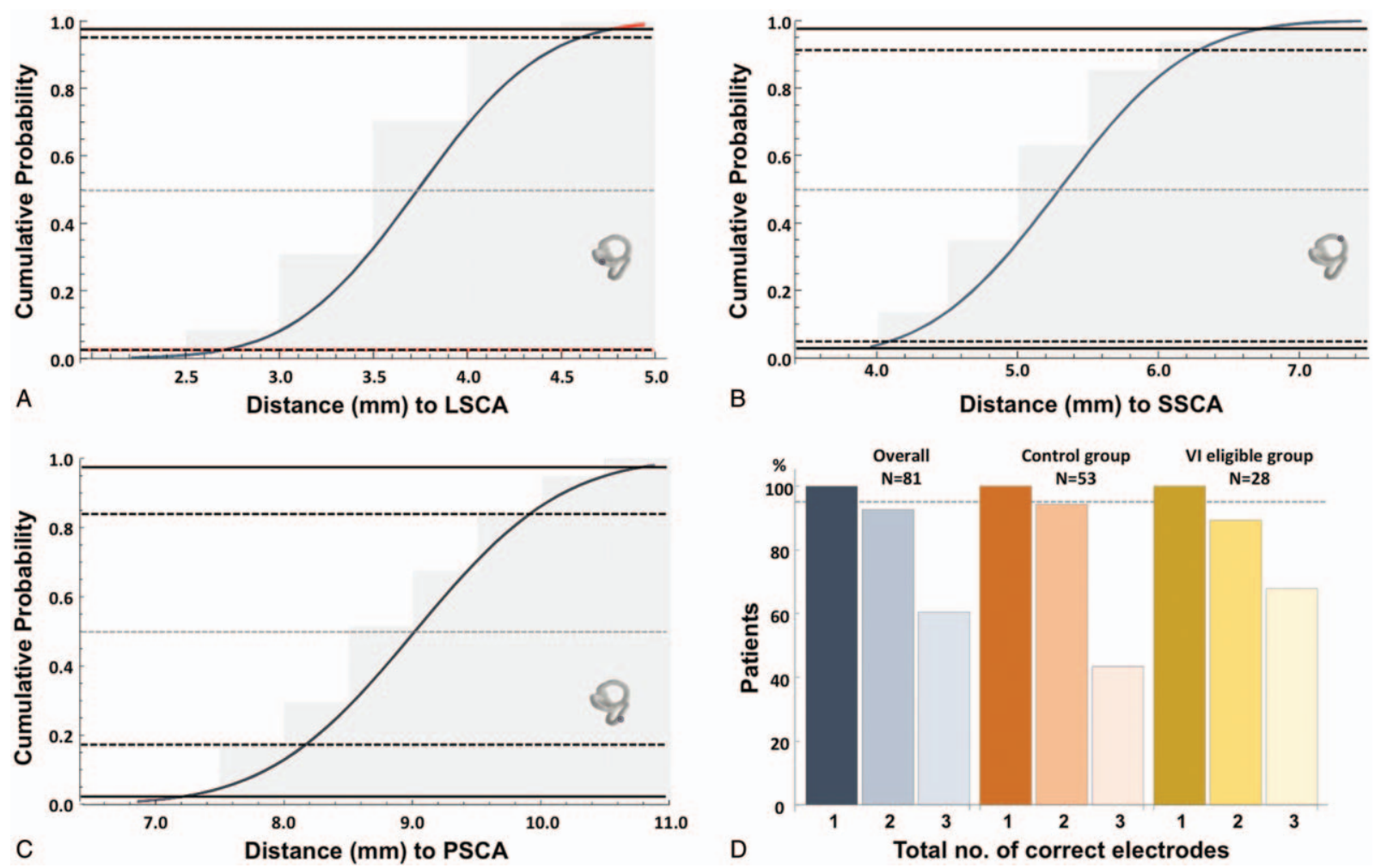

FIG. 4. Hits and misses: distances of fenestration sites to ampullae. The distribution of the distance of fenestration site in millimetres to ampulla for: $(A)$ the lateral semicircular canal (LSCA), (B) the superior semicircular canal (SSCA), and $(C)$ posterior semicircular canal (PSCA). Between the black dashed lines correct placements are shown (i.e., placements with the chosen electrode length, based on the median, within $1.0 \mathrm{~mm}$ from the ampulla). The zones outside of the solid black lines indicate the outer $2.5 \%$ of the distribution of distances. $D$, Number of correct placements of the electrode in the ampulla per patient. Dashed line indicate the target (95\%). Note the different scales of the $x$ axes in $A$ to $C$.

TABLE 3. Spatial relationships of landmarks sensitive to adverse events

\begin{tabular}{|c|c|c|c|c|c|c|}
\hline Overall $\mathrm{n}=81$ & Mean $(95 \% \mathrm{CI})$ & $\mathrm{SD}$ & Median & IQR Q1-Q3 & Min & Max \\
\hline Incus-facial nerve (mm) & $4.10(4.00-4.20)$ & 0.44 & 0.44 & $3.86-4.33$ & 2.78 & 5.19 \\
\hline Facial nerve-lateral SSC (mm) & $2.32(2.21-2.43)$ & 0.52 & 0.52 & $2.06-2.71$ & 0.55 & 3.21 \\
\hline Superior SSC-tegmen $(\mathrm{mm})$ & $1.29(0.74-1.55)$ & 0.67 & 0.67 & $0.74-1.55$ & 0.08 & 3.59 \\
\hline
\end{tabular}

The distance from the tip of the incus to the closest point of the facial nerve. The closest distance between the lateral semi-circular canal and facial nerve and the proximity of the tegmen to the superior semi-circular canal. CI indicates confidence interval; mm, millimeter.

\section{DISCUSSION}

In this study an algorithm was created and applied to calculate the optimal electrode lead length in combination with a surgical procedure. The optimal electrode lead length was compared with the individual anatomical data of all patients to evaluate the robustness of our electrode placement in silico. This first iteration in designing the vestibular implant electrode leads and surgical procedure for the target population did not reach its objective in the

TABLE 4. Landing on the superior canal using the surgical guide

\begin{tabular}{|c|c|c|c|c|c|c|c|c|c|c|c|c|c|}
\hline & \multicolumn{4}{|c|}{ VI Eligible Group $n=28$} & \multicolumn{2}{|c|}{ Success Rate } & \multicolumn{4}{|c|}{ Control Group $n=53$} & \multicolumn{2}{|c|}{ Success Rate } & \multirow[b]{2}{*}{$p$-Value } \\
\hline & $\begin{array}{c}\text { Mean } \\
(\mathrm{CI})\end{array}$ & $\mathrm{SD}$ & Median & $\begin{array}{c}\text { IQR } \\
\text { (Q1-Q3) }\end{array}$ & $<0.5 \mathrm{~mm}$ & $<1.0 \mathrm{~mm}$ & $\begin{array}{c}\text { Mean } \\
(\mathrm{CI})\end{array}$ & $\mathrm{SD}$ & Median & $\begin{array}{c}\mathrm{IQR} \\
(\mathrm{Q} 1-\mathrm{Q} 3)\end{array}$ & $<0.5 \mathrm{~mm}$ & $<1.0 \mathrm{~mm}$ & \\
\hline $\begin{array}{l}\text { Distance to } \\
\text { superior SSC }\end{array}$ & $\begin{array}{c}0.51 \\
(0.39-0.63)\end{array}$ & 0.32 & 0.45 & $0.23-0.61$ & $54 \%$ & $93 \%$ & $\begin{array}{c}0.38 \\
(0.25-0.51)\end{array}$ & 0.48 & 0.32 & $0.09-0.58$ & $66 \%$ & $96 \%$ & 0.82 \\
\hline
\end{tabular}

A comparison of groups for the minimal distance between the surgical guide and the superior semicircular canal (SSC). The thresholds for the success rate are defined as landing within 0.5 or $1.0 \mathrm{~mm}$ of the center of the superior semicircular canal. Means of both groups are compared and not statistically different. 
initial attempt. A success rate of $95 \%$ for correct electrode placement was not achieved in any of the semicircular canals: $92.6 \%$ (LSCC), 66.7\% (PSCC), and 86.4\% (SSCC). However, by revising the electrode design, by adding two extra electrode contacts per lead at a distance of -1.0 and $1.0 \mathrm{~mm}$ from the current electrode, the initial objective could still be reached. This could also enable future features such as current steering that could potentially be used to optimize selectivity and dynamic range further. On the contrary, the research will need to examine the risk of cross-excitation between ampullae if using the 3-electrode-leads, especially for the adjacent ampullae of the LSCC and SSCC.

The proposed vestibular implant electrode model together with the surgical procedure should be validated in a temporal bone study. Other additional methods to improve the accuracy and robustness of placement is to monitor the maximum eye velocity and spatial direction of its movement when placing the electrode lead in the semicircular channel while stimulating, intraoperative imaging (e.g., CT or fluoroscopy), or neural response telemetry (10). These approaches present an additional risk of inflicting additional damage to the sensitive membranous labyrinth from retracting and extending the lead in trying to achieve an optimum. Moreover, similar to the situation in cochlear implants, good neural response telemetries do not necessarily ensure a good or optimal position, making this a subject for further investigation (16).

Publication of a computational anatomy based approach to designing a surgical procedure and electrode for a neural prosthesis is uncommon. The approach presented here could improve accuracy and robustness in relation to the amount of data available instead of with the amount of trial-and-error attempts in patients. This should reduce imposing negative side effects to the patient (harms). In comparison, many years after its introduction, the more straightforward surgical procedure and electrode design for the cochlear implant has largely halted in absence of innovations to apprehend the electrode-to-neuron interface problem (dialectics of progress). Cochlear implant performance has remained relatively unchanged in the last 20 to 30 years (20).

This quantitative anatomy approach is a different strategy to designing an electrode than the attempts to use a model of the inner ear. Variables that are not considered, because of the interpretation by the modeler, to account for a certain variance in a model might be especially relevant and are easily neglected. Moreover, the chance that patients who are eligible for a vestibular implant have a subtle but deviant anatomy is larger because of genetic predispositions or pathology that led to their disease in the first place. The approach here aims to preserve any hidden relationships that might exist in the anatomical features of the individual patient, by considering every variant of anatomy which is in the dataset of eligible patients. This ensures that the overall approach is appropriate for the target population and that variabilities in anatomy are considered in proportion to their actual prevalence.

The current design strategy is founded on the quantitative anatomy of the population. In the future, individual variation in inner ear anatomy may be further appreciated by using individualized simulations for the surgical procedure.

\section{Limitations}

Variables such as the physical properties of the silicone electrode leads were not considered in silico. This can be expected to yield a difference with surgery ex or in vivo. The physical design of the electrode has gained attention before and factors identified by others should be taken into account $(21,22)$. The surgical steps were evaluated by two investigators (B.S., R.vd.B) but the simulation was executed by B.S. The in silico approach is currently not suitable to simulate differences between surgeons. However, the impact of these limitations is partially compensated for by future temporal bone studies, with real vestibular implant electrodes, which can include surgeons with different levels of experience and different preferences. This will also allow for the necessary fine-tuning on the electrode lengths and surgical approach for which this study provided the draft.

\section{CONCLUSION}

A computational anatomy approach can be used to design and test surgical procedures in silico. It could pave the way for faster developments in operative treatments, possibly eliminating unsuccessful surgery strategies before they have thoroughly been evaluated in clinical practice.

Our proposed surgical procedure proved insufficient to reach the initial aim of a $95 \%$ success rate in electrode placement, however after a minor modification in electrode lead design, the initial goal could still be reached. Future research is planned to evaluate the proposed vestibular implant electrode model with three electrodes per lead together with the surgical procedure in a temporal bone study before clinical implementation.

\section{REFERENCES}

1. McCulloch P, Cook JA, Altman DG, Heneghan CDM, IDEAL group. IDEAL framework for surgical innovation 1: the idea and development stages. BMJ 2013;346:f3012.

2. Pennell CP, Hirst AD, Campbell WB, et al. Practical guide to the idea, development and exploration stages of the IDEAL framework and recommendations. Br J Surg 2016;103:607-15.

3. Gong W, Merfeld DM. Prototype neural semicircular canal prosthesis using patterned electrical stimulation. Ann Biomed Eng 2000; 28:572-81.

4. van de Berg R, Guinand N, Stokroos RJ, Guyot JP, Kingma H. The vestibular implant: quo vadis? Front Neurol 2011;2:47.

5. Suzuki JI, Goto K, Tokumasu K, Cohen B. LXXII: implantation of electrodes near individual vestibular nerve branches in mammals. Ann Otol Rhinol Laryngol 1969;78:815-26.

6. Fridman GY, Della Santina CC. Progress toward development of a multichannel vestibular prosthesis for treatment of bilateral vestibular deficiency. Anat Rec (Hoboken) 2012;295:2010-29. 
7. Sun DQ, Ward BK, Semenov YR, Carey JP, Della Santina CC. Bilateral vestibular deficiency. JAMA Otolaryngol Head Neck Surg 2014;140:527-34.

8. Ward BK, Agrawal Y, Hoffman HJ, Carey JP, Della Santina CC. Prevalence and impact of bilateral vestibular hypofunction. JAMA Otolaryngol Head Neck Surg 2013;139:803-10.

9. Fornos AP, Guinand N, Van De Berg R, et al. Artificial balance: restoration of the vestibulo-ocular reflex in humans with a prototype vestibular neuroprosthesis. Front Neurol 2014; 5:66.

10. Guinand N, Van De Berg R, Cavuscens S, et al. Vestibular implants: 8 years of experience with electrical stimulation of the vestibular nerve in 11 patients with bilateral vestibular loss. ORL $J$ Otorhinolaryngol Relat Spec 2015;77:227-40.

11. Tang S, Melvin TA, Della Santina CC. Effects of semicircular canal electrode implantation on hearing in chinchillas. Acta Otolaryngol 2009;129:481-6.

12. Dai C, Fridman GY, Della Santina CC. Effects of vestibular prosthesis electrode implantation and stimulation on hearing in rhesus monkeys. Hear Res 2011;277:204-10.

13. van de Berg R, Guinand N, Guyot JP, Kingma H, Stokroos RJ. The modified ampullar approach for vestibular implant surgery: feasibility and its first application in a human with a long-term vestibular loss. Front Neurol 2012;3:18.
14. Spoor F, Zonneveld F. Comparative review of the human bony labyrinth. Am J Phys Anthropol 1998;27 (suppl):211-51.

15. Lee JY, Shin KJ, Kim JN, Yoo JY, Song WC, Koh KS. A morphometric study of the semicircular canals using micro-CT images in three-dimensional reconstruction. Anat Rec (Hoboken) 2013;296:834-9.

16. Stieglitz LH, Fichtner J, Andres R, et al. The silent loss of neuronavigation accuracy: a systematic retrospective analysis of factors influencing the mismatch of frameless stereotactic systems in cranial neurosurgery. Neurosurgery 2013;72:796-807.

17. Fedorov A, Beichel R, Kalpathy-Cramer J, et al. 3D Slicer as an image computing platform for the Quantitative Imaging Network. Magn Reson Imaging 2012;30:1323-41.

18. Thompson DW. On growth and form. J Philos 1945;42:557-8.

19. Grenander U, Miller MI. Computational anatomy: an emerging discipline. Q Appl Math 1998;56:617-94.

20. Zeng FG. Challenges in improving cochlear implant performance and accessibility. IEEE Trans Biomed Eng 2017;64:1662-4.

21. Golub JS, Ling L, Nie K, et al. Prosthetic implantation of the human vestibular system. Otol Neurotol 2014;35:136-47.

22. Chiang B, Fridman GY, Dai C, Rahman MA, Della Santina CC. Design and performance of a multichannel vestibular prosthesis that restores semicircular canal sensation in rhesus monkey. IEEE Trans Neural Syst Rehabil Eng 2011;19:588-98. 